\title{
Effects of the $\mathrm{N}, \mathrm{O}$, and $\mathrm{S}$ heteroatoms on the adsorption and desorption of
} asphaltenes on silica surface: A molecular dynamics simulation

\author{
Bai, Yun; Sui, Hong; Liu, Xiaoyan; He, Lin; Li, Xingang; Thormann, Esben
}

Published in:

Fuel

Link to article, DOI:

10.1016/j.fuel.2018.11.135

Publication date:

2019

Document Version

Peer reviewed version

Link back to DTU Orbit

Citation (APA):

Bai, Y., Sui, H., Liu, X., He, L., Li, X., \& Thormann, E. (2019). Effects of the N, O, and S heteroatoms on the adsorption and desorption of asphaltenes on silica surface: A molecular dynamics simulation. Fuel, 240, 252261. https://doi.org/10.1016/j.fuel.2018.11.135

\section{General rights}

Copyright and moral rights for the publications made accessible in the public portal are retained by the authors and/or other copyright owners and it is a condition of accessing publications that users recognise and abide by the legal requirements associated with these rights.

- Users may download and print one copy of any publication from the public portal for the purpose of private study or research.

- You may not further distribute the material or use it for any profit-making activity or commercial gain

- You may freely distribute the URL identifying the publication in the public portal 
1 Effects of the $\mathbf{N}, \mathbf{O}$, and $\mathrm{S}$ heteroatoms on the

2 adsorption and desorption of asphaltenes on silica

3 surface: A molecular dynamics simulation

4

5 Yun Bai ${ }^{1,2,3}$, Hong Sui ${ }^{1,2,3}$, Xiaoyan $\mathrm{Liu}^{4}$, Lin $\mathrm{He}^{1,2^{*}}$, Xingang $\mathrm{Li}^{1,2,3}$, Esben Thormann ${ }^{5}$

$6{ }^{1}$ School of Chemical Engineering and Technology, Tianjin University, Tianjin, 300072, China.

$7 \quad{ }^{2}$ National Engineering Research Center of Distillation Technology, Tianjin, 300072, China.

$8 \quad{ }^{3}$ Collaborative Innovation Center of Chemical Science and Engineering (Tianjin), 300072, China.

$9 \quad{ }^{4}$ School of Chemistry and Chemical Engineering, Shaanxi Normal University, Xi'an 710062, China

${ }^{5}$ Department of Chemistry, Technical University of Denmark, 2800 Kongens Lyngby, Denmark 
Abstract: The adsorption and desorption of asphaltene on silica is highly dependent on the heteroatoms present in its structure. Herein, model asphaltene molecules with different heteroatoms $(\mathrm{N}, \mathrm{O}, \mathrm{S})$ at different positions (in the aromatic cores, in the middle and termination of alkane side chains) are chosen as the adsorbates to investigate their adsorption and desorption behaviors on silica through molecular dynamics (MD) simulation. Results reveal that the characteristic adsorption configuration of asphaltenes is ascribed to the competition between the asphaltene-silica interaction and $\pi-\pi$ stacking interaction among the asphaltene polyaromatic rings. The presence of heteroatoms is found to be able to strengthen the interactions between asphaltenes and silica, depending on their type and location. For example, the terminal polar groups, especially the carboxyl $(\mathrm{COOH})$, exhibit the greatest enhancement to the electrostatic interaction (increasing from -81 to $-727 \mathrm{~kJ} / \mathrm{mol}$ ). The $\mathrm{S}$ atoms are also found to increase the van der Waals interaction energies by $25 \%$. According to the equilibrium desorption conformation and density profile, the presence of heteroatoms is found to significantly hinder the desorption of asphaltenes from silica due to the enhanced polar interactions. The impeded desorption is also confirmed by the slower detachment of asphaltenes based on the time-dependent interaction energies and center of mass (COM) distances analysis. Additionally, the terminal polar groups lead to extraordinary desorption properties of asphaltenes. It is observed that the strong asphaltene-silica and asphaltenewater interactions coexist in these systems due to the high polarity and hydrophilicity of the terminal polar groups.

Keywords: Asphaltene; heteroatom; adsorption; molecular dynamic simulation 


\section{Introduction}

Asphaltenes are defined as the insoluble fractions of petroleum in low-molecularweight paraffins such as n-heptane but soluble in light aromatics such as toluene. The structure of asphaltenes is complex and it is widely accepted that they consist of a mixture of polycyclic aromatic hydrocarbons, together with some pending aliphatic chains [1-2]. Asphaltenes are considered as the heaviest components of petroleum, with the highest molecular weight (500-2000 $\mathrm{g} / \mathrm{mol}$ for asphaltene monomer [3-4]) and polarity. In addition, different kinds of heteroatoms (e.g., N, O, S) and a trace of heavy metals (e.g., Ni, V, Fe) are found in asphaltenes [5-6]. These heteroatoms and complex structure of asphaltenes cause complicated interfacial behaviors at the oil-solid and oilwater interfaces [7].

Asphaltene adsorption on solid surfaces is a ubiquitous phenomenon that occurs during unconventional oil production as well as the remediation of oil-contaminated soils (e.g., oil sludge) [7-9]. During the past few decades, many investigations have been conducted to understand the adsorption behavior of asphaltenes on different solid surfaces including silica, minerals, clays, metallic oxides [10-12]. It has been proved that the various interactions between asphaltenes and surfaces (e.g., van der Waals, electrostatic, hydrogen bonding, charge transfer, steric and hydrophobic interactions) are responsible for the adsorption [13-14]. Additionally, the strong tendency of asphaltenes to form self-aggregates, which is due to the intermolecular $\pi-\pi$ overlap between aromatic planes and hydrogen bonding between functional groups [15-17], make it easier for asphaltenes to precipitate on mineral surfaces [18]. Both the 
monolayer and multilayer adsorption of asphaltenes on mineral surfaces have been observed and studied [4, 19].

The heteroatoms in asphaltene structure play an important role in the adsorption process. Some experimental adsorption studies have been conducted using different sources of asphaltenes or model asphaltenes as adsorbates. It is found that the heteroatoms-containing polar moieties (e.g. pyridinic, pyrrolic, phenolic, carboxylic, and quinolic groups) significantly influence the surface adsorption [20-21]. The amount of adsorbed asphaltenes increases with increasing nitrogen content $[4,9]$, in some cases oxygen content [22]. Moreover, with the help of MD simulations, some studies have been conducted to understand the adsorption of some simple polar aromatic hydrocarbons to mineral surfaces [12, 23-26]. It is found that nitrobenzene compounds possess favourable adsorption enthalpies with mineral surface compared with xylene [23]. The carboxyl group also exerts strong adsorptive interaction to mineral with participation of electrostatic interactions [12]. When the heteroatoms are present in the side chains of model asphaltene molecules, the density of adsorbed asphaltenes from solvent is significantly enhanced according to the dissipative particle dynamics (DPD) simulations [24]. Besides, the self-aggregation mechanism of asphaltenes is also found to be strongly correlated to the N, O and S heteroatoms [16-17], which potentially affects the precipitation of model asphaltenes. These previous investigation suggests that the presence of heteroatoms greatly influence the interaction between asphaltenes and solid surfaces. However, little studies have been conducted to systematically compare the adsorptive interactions between mineral surface and asphaltene molecules 
with different heteroatoms ( $\mathrm{N}, \mathrm{O}$ and $\mathrm{S}$ ) at different locations (in the aromatic cores, in the middle and termination of alkane side chains).

On the other hand, although the water solution has been widely applied to separate the heavy oil from different ore surface, the effect of heteroatoms in asphaltene molecules on water-based desorption processes are still unclear. This process could understood from two aspects: Asphaltenes at the liquid-mineral interface and oil-water interface. For the detachment of oil from mineral surface, generally, the asphaltenes are more likely to stay attached on the mineral solid surfaces compared with those light petroleum components (e.g., polycyclic aromatic hydrocarbons (PAHs)) in the desorption process [9, 27-28]. While for the oil-water separation stage, since the asphaltenes are surface-active components in crude oil, they often act as natural surfactants at the oil-water interface due to the presence of heteroatoms in the asphaltene molecules [29-30]. However, the effects of heteroatom type and location in asphaltenes on the above process at the interfaces are still unclear.

To address the above issues, model asphaltene molecules with presence of heteroatoms $(\mathrm{N}, \mathrm{O}, \mathrm{S})$ at different positions are chosen as the adsorbates to investigate their adsorption and desorption behaviors on silica through molecular dynamics (MD) simulation. The specific objective of the present study is to understand the effect of different heteroatoms as well as their positions on the adsorption and desorption behaviors of asphaltenes on silica, which allows potential suggestions for the enhancement of oil separation from real ores. 


\section{Simulation method}

\subsection{Force field}

The MD simulations were carried out using the GROMACS (version 5.1.4) software package [31-32]. The GROMOS96 force field with the 53a6 parameter set was used in all calculations to compute the bonded and non-bonded potential of molecules [33]. This force field has already been proved to be credible to predict the dynamics of polyaromatic molecules [34].

\subsection{Molecular models}

The construction of mineral surface and selection of asphaltene molecule are key steps of the MD simulation. Three-dimensional structures of silica and asphaltene models were built and preliminarily optimized using Material Studio 7.0.

Here, the monoclinic $\alpha$-quartz $\left(\begin{array}{lll}0 & 1 & 0\end{array}\right)$ surface was used as the initial input structures of silica. Then the $(10 \times 10)$ silica supercells were converted into the $3 \mathrm{D}$ periodic cells by building vacuum slabs. The cross-section of the surface was determined to be 5.402 $\times 4.909996 \mathrm{~nm}^{2}$. To mimic the real state of the mineral surfaces, the silica surface was modified with hydroxyl groups. Each top silicon atom was connected with two hydroxyls, and the density of grafted hydroxyls amounted to $7.54 \mathrm{OH} / \mathrm{nm}^{2}$ (shown in Table 1). The structure of surface hydroxyls was optimized with energy minimization. Asphaltenes are the heaviest fraction in petroleum. During the past decades, large quantities of different asphaltene molecules have been reported through instrumental detection and many of them have been used as models in MD simulation [35]. The PA3, one proposed petroleum asphaltene structure on the basis of atomic force microscope 
121 (AFM) measurements and scanning tunneling microscope (STM) orbitals images [36], 122 was selected in this MD simulation (shown in Table 1). This PA3 molecule has been 123 successively applied as a model asphaltene molecule in many MD simulations $[10,16-$ $12417,37]$. In this study, to investigate the effect of asphaltene heteroatoms and their 125 positions on the adsorption and desorption system, ten different molecular structures of 126 asphaltenes were studied respectively. As shown in Table 1, the nitrogen (N), oxygen $127(\mathrm{O})$, sulfur $(\mathrm{S})$ atoms were used to substitute the carbon atoms at different positions in 128 these structures: in the aromatic core, in the middle of alkane side chain and at the 129 termination of alkane side chain, respectively. The terminal polar groups include the 130 amino $\left(\mathrm{NH}_{2}\right)$, carboxyl $(\mathrm{COOH})$, and thiol $(\mathrm{SH})$. All the asphaltene molecules are kept 131 neutral in this study. Herein, the hydrolysis of polar groups and relevant charged 132 molecules are not involved.

133 The coordinate files of silica surface and asphaltenes were exported and converted 134 to GROMACS topology files through GROMACS command (gmx $\mathrm{x} 2$ top) and 135 PRODRG server [38]. Then the resulted topology files (including atom types, atom 136 charges, bonds, angles and dihedrals) were manually adjusted according to the analogue 137 structures in the force field library, which was elaborated in the supporting information 138 (SI) [39-40]. The charge distribution in silica surface and asphaltene molecules were 139 illustrated in Figure SI-1. The simple point charge (SPC) model was applied to model 140 water molecules in the desorption system [39]. 


Silica surface

Note: Blanks are referred to the same structures with "PA3 (C)". $R_{1}$ and $R_{2}$ are the alkane side chains containing heteroatoms. $X_{n}(n=1-3)$ represent the polar groups which can be $\mathrm{NH}, \mathrm{O}$, or $\mathrm{S}$ groups.

\subsection{MD simulation}

The goal of this study is to get to know how the heteroatoms influence the adsorption and desorption behaviors of asphaltenes on silica. Therefore, the MD simulation process was conducted in two stages: (i) the adsorption of ten different kinds of asphaltene molecules on silica respectively, and (ii) the desorption of these asphaltenes when these systems are filled with water.

151 Prior to the adsorption, 20 asphaltene molecules were placed on top of silica in the

152 simulation box. After the initialization, all the MD simulations were carried out under

153 NVT ensemble. The simulation time used for the adsorption of asphaltenes was $5 \mathrm{~ns}$.

154 The asphaltene molecules were adsorbed on the silica surface steadily when the system 
155

156

157

reached equilibrium. After the adsorption, the water molecules were added randomly at the top of the previous adsorption system $(5.40 \mathrm{~nm} \times 4.91 \mathrm{~nm} \times 8.00 \mathrm{~nm})$. Then the ternary system was applied to simulate the desorption process with a duration of $10 \mathrm{~ns}$.

During the adsorption and desorption simulation, the silica surface were considered as ideal planes and were frozen up.

In all simulations, the energy minimization was conducted using the steepest descent approach with the convergence level of $1000 \mathrm{~kJ}(\mathrm{~mol} \cdot \mathrm{nm})^{-1}$. The temperature of the systems was controlled and kept constant at $300 \mathrm{~K}$ by the V-rescale thermostat algorithm [41]. For the calculations of short-range van der Waals and electrostatic interactions, the cutoff distance was fixed at $1.4 \mathrm{~nm}$. The particle mesh Ewald summation (PME) method was used to compute the long range electrostatics [42]. All simulations were carried out under periodic boundary conditions with the time step of $1 \mathrm{fs}$. The trajectories were collected in an interval of $1 \mathrm{ps}$ for further analysis.

\subsection{Data analysis}

To quantify the intensity of interactions between asphaltenes and silica, the interaction energies between them will be calculated. The more negative the interaction energy is, the stronger the adsorption is. The Lennard-Jones potential and Coulomb interaction between two particles are calculated using the following equations:

$$
\begin{gathered}
V_{L J}\left(r_{i j}\right)=\frac{C_{i j}^{(12)}}{r_{i j}^{I 2}}-\frac{C_{i j}^{(6)}}{r_{i j}^{6}} \\
V_{C}\left(r_{i j}\right)=f \frac{q_{i} q_{j}}{\varepsilon_{r} r_{i j}}
\end{gathered}
$$

where, $r_{i j}$ represents the distance between the particles i and j; $C_{i j}^{(12)}$ and $C_{i j}{ }^{(6)}$ take the 
average of the van der Waals terms of particles $\mathrm{i}$ and $\mathrm{j} ; q_{i}$ and $q_{j}$ represent the (partial) charges of the particles $\mathrm{i}$ and $\mathrm{j}$ respectively; $f$ is the Coulomb's constant $(f=138.935$ $\left.\mathrm{kJ} \cdot \mathrm{mol}^{-1} \cdot \mathrm{nm} \cdot \mathrm{e}^{-2}\right) ; \varepsilon_{r}$ represents the relative permittivity. The van der Waals and electrostatic interactions between the asphaltene and silica groups are calculated on basis of $V_{L J}$ and $V_{C}$, respectively.

The number of hydrogen bonds and molecular contacts between asphaltenes and silica are also analyzed. Here, a contact is considered when the minimum distance between any atoms of the two groups is $\leq 0.3 \mathrm{~nm}$. Additionally, the density distributions of asphaltene and water molecules along the z-axis are also analyzed in the desorption system. All these equilibrium properties are calculated by averaging over the last $1 \mathrm{~ns}$ of the simulations. Besides, the time-dependent distances between asphaltenes and silica are also used to characterize the desorption kinetics.

\section{Results and Discussions}

\subsection{Adsorption of asphaltenes on silica surface}

The asphaltene molecules move closely towards the silica surface during the adsorption process. The equilibrium adsorption conformation of PA3 (C) molecules is shown in Figure 1. The asphaltene polyaromatic planes are found to appear different orientations to the silica surface at the equilibria state. Some molecules are nearly face-to-face contacting with the silica surface, while others are adsorbed on the surface with the edge of the polyaromatic planes or alkane side chains. Three single molecules are extracted to illustrate the three forms of orientations respectively (Figure 1). The different equilibrium conformations of adsorption is mainly attributed to the balance 
between the asphaltenes-silica interaction and the intermolecular $\pi$ - $\pi$ stacking interaction among asphaltene molecules. Basically, the parallel orientation is mainly ascribed to the van der Waals and electrostatic interactions between the polyaromatic planes and silica, while some asphaltene molecules exhibit perpendicular orientations to the silica surface due to their intermolecular self-aggregation. It is worth noting that the distribution of different orientations is dependent on the loading of asphaltene molecules. When asphaltenes are at low loadings initially, the asphaltene-silica interaction plays the dominate role, thus more flat adsorbed molecules are observed. Increasing the initial loading of asphaltenes facilitates the asphaltene association and aggregation. More dimer, trimer and multiple aggregates of asphaltenes are formed, increasing the dihedral angles of asphaltene polyaromatic planes with respect to the silica. The equilibrium adsorption conformations of PA3 (C) molecules at different loadings (i.e., 5, 10, 20, 30) are compared in Figure SI-2. The corresponding interaction energies between asphaltenes (loading $=20$ ) and silica have been calculated (Table 2). The total interaction forces could be divided into two parts: the van der Waals force and the electrostatic force. The van der Waals force is found to be the dominant force between asphaltenes and mineral surface, outweighing the electrostatic force. It is obvious that the asphaltene molecules, which adopt the parallel orientation, are adsorbed with more atoms directly contacting with the silica surface. Thus, they possess stronger affinity to the silica surface. The interaction energy between the parallel molecule and silica is more than three times higher than that of the perpendicular molecule. There are also some differences between the perpendicular asphaltene 
molecules. It is noticed that the $\mathrm{C}-\mathrm{H}$ bonds located at the edge of the polyaromatic plane possess higher polarity compared with those in alkane side chains. In this case, the

(a)

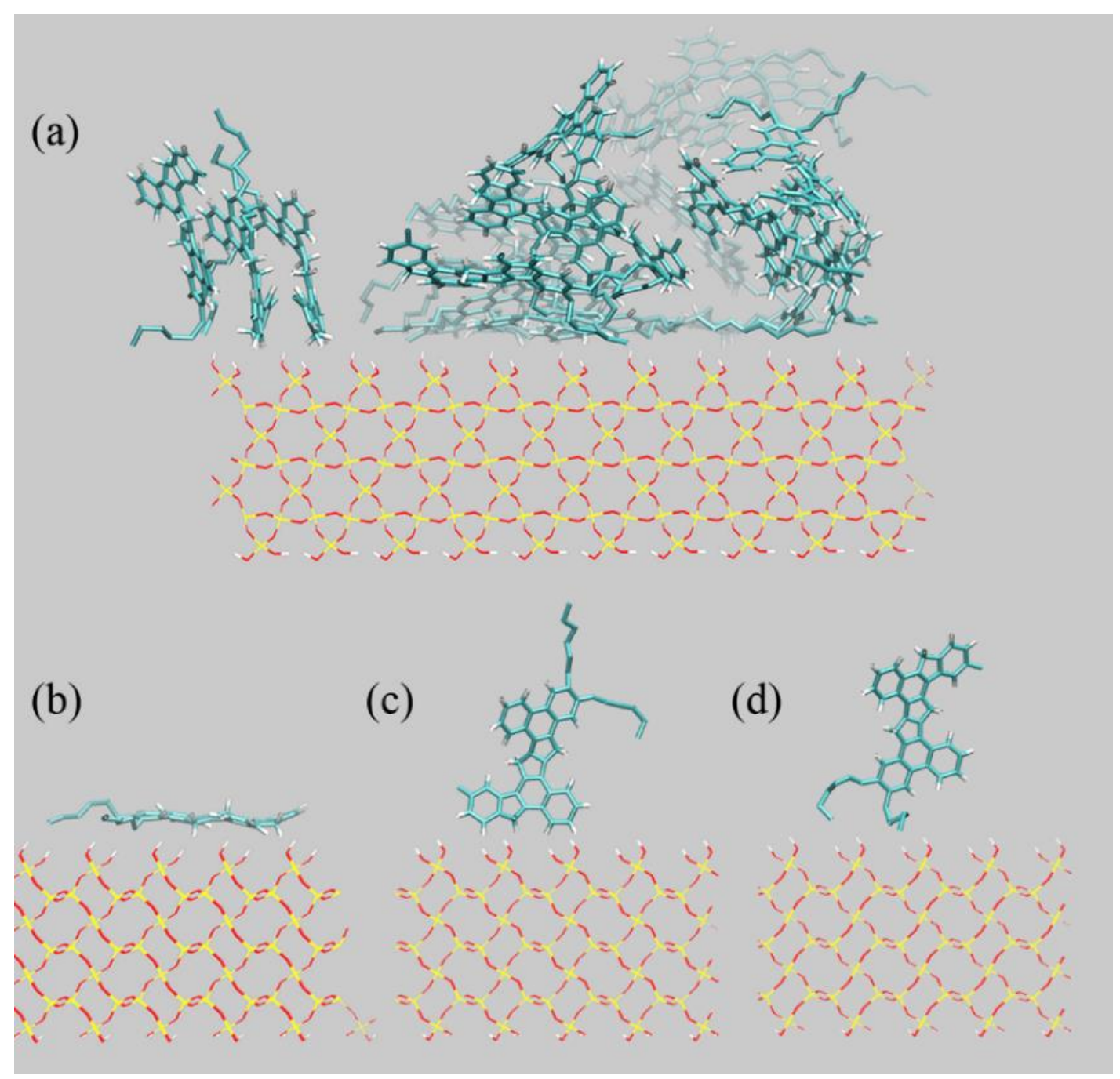

Figure 1. (a) Equilibrium conformation of asphaltene molecules on silica surface after yellow, silicon; and cyan, carbon). 
Table 2. Electrostatic energies, van der Waals energies, and total interaction energies

232 between single-asphaltene PA3 (C) and silica

\begin{tabular}{cccc}
\hline Interaction energy $(\mathrm{kJ} / \mathrm{mol})$ & $\mathrm{E}_{\text {ele }}$ & $\mathrm{E}_{\mathrm{vdw}}$ & $\mathrm{E}_{\text {total }}$ \\
\hline (a) average & $-4.06 \pm 0.52$ & $-66.89 \pm 1.38$ & $-70.95 \pm 1.46$ \\
(b) parallel & $-17.98 \pm 4.86$ & $-244.65 \pm 8.82$ & $-262.64 \pm 10.15$ \\
$\begin{array}{c}\text { (contact segment: polyaromatic plane) } \\
\text { (c) perpendicular }\end{array}$ & $-9.14 \pm 2.80$ & $-64.97 \pm 6.16$ & $-74.11 \pm 6.46$ \\
$\begin{array}{c}\text { (edge of the polyaromatic plane) } \\
\text { (d) perpendicular } \\
\text { (alkane side chain) }\end{array}$ & $0.84 \pm 0.25$ & $-57.53 \pm 6.18$ & $-59.69 \pm 6.16$ \\
\hline
\end{tabular}

\subsection{Effect of heteroatoms on the adsorption}

235 The interaction energies between the ten different kinds of asphaltenes (all asphaltene molecules in each system) and silica have been calculated, shown in Figure 2. It is

237 worth noticing that the heteroatoms strengthen the interaction between asphaltenes and 238 silica in all systems.

239 Compared with the original asphaltene molecule $(\mathrm{C})$, the terminal polar groups 240 enhance the electrostatic interaction to a large extent (Figure 2a). Especially, the 241 carboxyl $(\mathrm{COOH})$ increase the electrostatic interaction energy from -81 to $-727 \mathrm{~kJ} / \mathrm{mol}$, 242 which is higher than that of amino $\left(\mathrm{NH}_{2}\right)$ and thiol $(\mathrm{SH})$ groups $(-350$ and $-329 \mathrm{~kJ} / \mathrm{mol}$, 243 respectively). While, the inside heteroatoms, distributed in the aromatic cores and 244 middle of alkane side chains, raise the electrostatic energy up to $-200 \mathrm{~kJ} / \mathrm{mol}$. The effect 245 of inside heteroatom-containing groups on the electrostatic interactions declines in the 246 order of: $\mathrm{NH}>\mathrm{O}>\mathrm{S}$, as well as heteroatoms in alkane side chains $>$ in aromatic cores.

247 The stronger electrostatic interactions are motivated by the increased polarity of 248 heteroatom-substituted groups. The carboxyl is known to possess the highest polarity, 
followed by the amino and thiol groups [43]. When the heteroatoms are located inside the structures of molecules, the nitrogen atom bears the most negative charge compared with oxygen and sulfur. The increased dipole moment as well as the additional polar N$\mathrm{H}$ bond lead to N-containing molecules' relatively higher polarity and thus, stronger electrostatic interactions with silica. On the other hand, the heteroatoms in aromatic cores exert relatively slighter influence on the adsorption energy compared with that in alkane side chains. This is ascribed to the steric hindrance, which reduces the contact of heteroatoms with the silica surface.

When the $\mathrm{N}$ and $\mathrm{O}$ atoms are present in asphaltene molecules, the hydrogen bonds are formed between the heteroatoms and hydroxyl groups on silica. The polar atoms would work as H-bonding acceptors in the adsorption process. For the terminal polar groups, about 23 and 14 hydrogen bonds in average are formed between the twenty PA3 $(\mathrm{COOH})$ and PA3 $\left(\mathrm{NH}_{2}\right)$ molecules with silica, respectively (Figure 3a). When $\mathrm{N}$ and $\mathrm{O}$ atoms are located in the middle of alkane side chains, an average of 4 hydrogen bonds are formed, while the number of averaged hydrogen bonds for asphaltenes with polar aromatic cores is approximately 1.5 . There is obviously no suitable groups to form hydrogen bonds in original asphaltene molecules PA3 (C) and those modified with S atoms. The hydrogen bonds contribute to the electrostatic forces between asphaltenes and silica. Accordingly, the trend of hydrogen bonds over different model asphaltenes is consistent with the electrostatic interaction energies.

Additionally, these heteroatoms are found to be able to strengthen the van der Waals interactions between asphaltenes and silica surface as well (Figure 2b). Particularly, 
271 the enhancement of $\mathrm{S}$ atoms is the most prominent compared with $\mathrm{N}$ and $\mathrm{O}$ atoms, 272 increasing the van der Waals interactions by $25 \%$. This relatively higher van der Waals 273 energy is motivated by the larger $\mathrm{C}^{(6)}$ and $\mathrm{C}^{(12)}$ van der Waals terms of the heteroatoms, 274 especially the $\mathrm{S}$ atoms with the highest molecular weight. It can be concluded from the 275 above interaction energy results that the heteroatoms enhance the polar interactions 276 between asphaltenes and silica, including both the van der Waals and electrostatic 277 interactions. The enhanced polar interactions contribute much to asphaltene adsorption 278 on the silica surface.

279 The contact frequencies of asphaltenes with the silica surface at the equilibria state 280 is another important factor in characterizing the interactions between asphaltenes and silica. As is shown in Figure 3b, an average 201 atoms in PA3 (C) molecules are found 282 in the first adsorption layer, where atoms are directly contacted with the silica surface.

283 Furthermore, the number of molecular contacts with silica is found to be increased 284 when increasing the presence of heteroatoms in asphaltenes. The density of atoms 285 adsorbed in the first adsorption layer is determined to be $7.6 \sim 10.9$ atoms $/ \mathrm{nm}^{2}$, which 286 is much lower than that of alkanes reported in literature [44-45]. The inhibited contacts 287 of asphaltenes with silica are ascribed to the strong intermolecular interactions among 288 asphaltene molecules. The $\pi-\pi$ stacking interaction among the polyaromatic rings in 289 asphaltene molecules competes with the attraction to the silica surface, leading to the 290 formation of aggregates, thus decreasing the surface coverage (defined as the 291 proportion of silica hydroxyls in contact with asphaltene molecules) to 46-61 \%. 
(a)

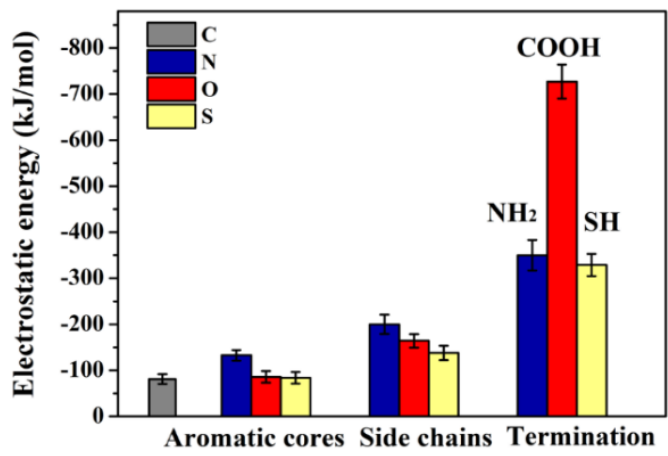

(b)

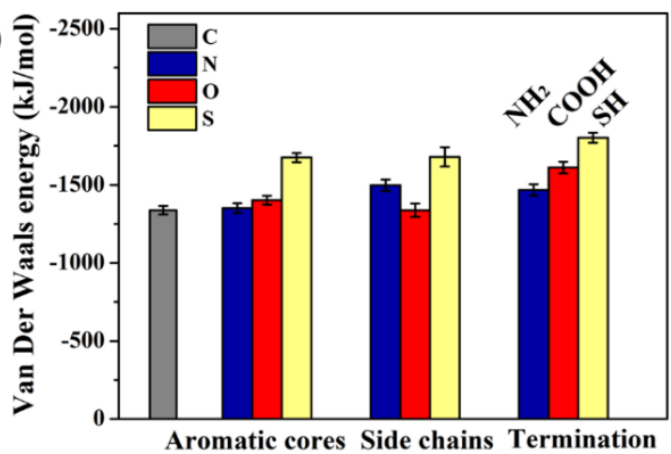

Figure 2. (a) Electrostatic energies and (b) van der Waals energies between asphaltenes

294 (all asphaltene molecules in each system) and silica.

(a)
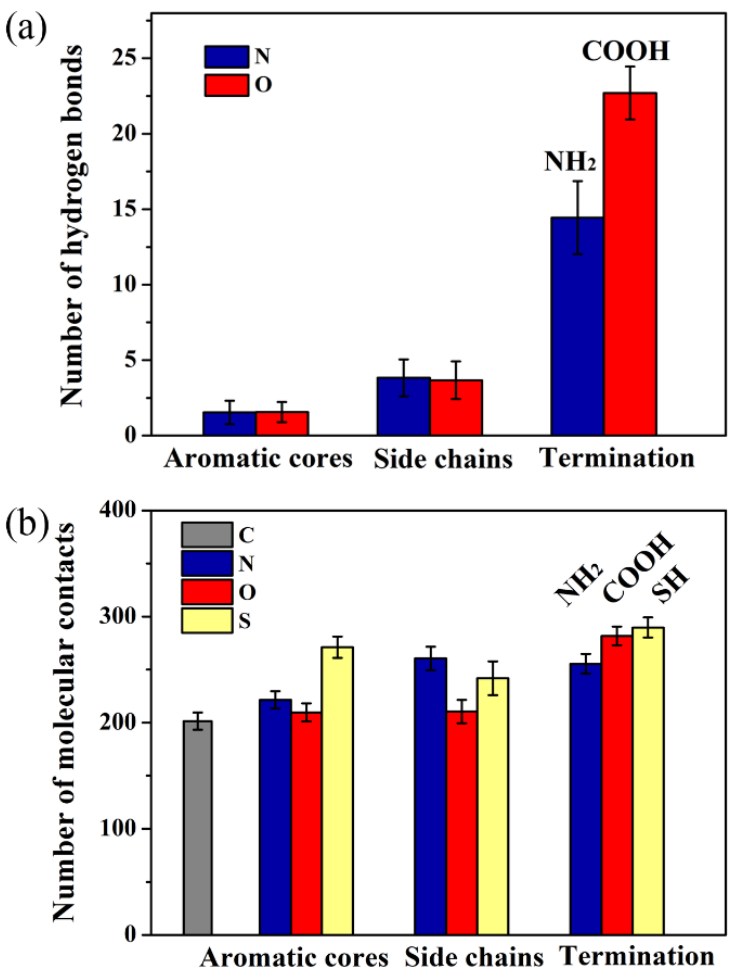

Figure 3. (a) Hydrogen bonds and (b) molecular contacts between asphaltenes and silica. 


\subsection{Effect of heteroatoms on the desorption}

\section{Effect of inside heteroatoms}

The adsorption of asphaltenes on silica surface turns the surface to be more hydrophobic.

This decrease in wettability of silica surface weaken the oil-solid separation in real oil production. Herein, the aqueous phase is added on top of the asphaltene molecules and fill the system to initiate the desorption process of asphaltene. Part of the silica surface has not been occupied by asphaltene molecules, where water molecules are able to contact with silica directly. In these regions, the water molecules strongly bind to the hydrophilic silica surface through electrostatic interactions. Particularly, the hydrogen bonds formed between the water molecules and the hydroxyl groups on the silica surface contribute to the adsorption of water molecules. The hydrogen bonding network within these water molecules also facilitate the affinity and stabilization of the water layer on the silica surface [46].

Accordingly, the desorption of pre-adsorbed asphaltene molecules from silica is controlled by the balance between their interaction with silica and the solvation by water. The dynamic desorption process is observed as follows: at the three-phase contact line of asphaltene-water-silica, the water molecules gradually occupy more adsorption sites on the surface due to their closer affinity with silica, replacing the pre-adsorbed asphaltene molecules. With the water molecules approaching, the repulsion between water molecules and hydrophobic asphaltene molecules could promote the diffusion of asphaltene molecules on the silica surface and aggregate together. The boundary of asphaltene aggregates are observed to shrink and they are more likely to form a droplet. 
When the water molecules continue driving the asphaltenes away, the water layer is formed between asphaltenes and silica. The asphaltene molecules are finally driven to partially detach from the silica surface [47-50].

The desorption of N-containing asphaltenes from silica surface in comparison with original PA3 (C) molecules are taken as examples to illustrate the effect of heteroatoms. Figure 4 shows the equilibrium conformation and the corresponding density distribution of the ternary desorption system after 10-ns simulation. Differing from the pre-adsorbed conformation, the asphaltene molecules are completely or partly desorbed from the silica surface. In addition, the asphaltenes are found to self-aggregate more tightly after the desorption simulation process. For the PA3 (C) desorption system, it is found that water molecules occupy most of the adsorption sites on silica, while the asphaltene molecules are distributed at larger distance from the surface. A stationary water layer with the thickness of $\sim 0.4 \mathrm{~nm}$ is formed between asphaltenes and the silica surface, which is ascribed to the balance of the asphaltene-silica attraction and hydration force [51-52]. Compared with the original PA3 (C) molecules, the Ncontaining asphaltene molecules concentrate closer with the silica surface. Both the PA3 (A_N) and PA3 (S_N) molecules are still partly adsorbed on silica with asphaltene segments contacting directly with the surface. Additionally, the center of mass of PA3 (S_N) molecules is located at the bottom of the asphaltene group and closer to silica, while that of PA3 (A_N) and PA3 (C) is elevated to the central of the aggregates.

Figure 5 presents the interaction energies between asphaltenes and silica as a function of simulation time. When the PA3 (C) molecules detach from the surface, the 
interaction energy between asphaltenes and silica declines rapidly from -1419 to -40 $\mathrm{kJ} / \mathrm{mol}$ in the first $5 \mathrm{~ns}$, while much stronger interaction energies and slower decrease are found in the PA3 (A_N) and PA3 (S_N) systems. After 10-ns simulation, the interaction energy between PA3 (A_N) and silica is observed to be $-245 \mathrm{~kJ} / \mathrm{mol}$. The PA3 (S_N) molecules exhibit the strongest affinity with the silica surface, up to -832 $\mathrm{kJ} / \mathrm{mol}$ (electrostatic and van der Waals interactions are -92 and $-740 \mathrm{~kJ} / \mathrm{mol}$, respectively). The reduction in interactions is also confirmed by the movements of asphaltene molecules at the molecular scale. Herein, the movements of asphaltenes are tracked by averaging the COM (center of mass) distance of them with the silica surface. It is clear that the asphaltene molecules move further away from the silica surface gradually in all simulation systems. The final COM distance in PA3 (C) system fluctuate at about $1.81 \mathrm{~nm}$ away from the surface. While, the final average COM distances are about 1.36 and $1.00 \mathrm{~nm}$ in PA3 (A_N) and PA3 (S_N) systems respectively. The above properties indicate that the stronger binding and more difficult desorption of the N-containing asphaltenes on silica, especially when the heteroatoms are distributed in alkane side chains.

Due to the enhanced polar interactions in presence of heteroatoms, the affinity of heteroatom-containing asphaltenes to the silica surface becomes stronger, impeding their desorption from the silica surface. Basically, the strengthened asphaltene-silica interaction makes it more difficult for water molecules to penetrate through the asphaltene-silica boundary, thus slowing down the replacement process. As in the adsorption process, the effect of heteroatoms located in the alkane side chains on 
asphaltene desorption is stronger compared with those located in aromatic cores. The

365 similar phenomena occur to the O-containing and S-containing molecules. The similar conclusion could also be derived from the time-dependent interaction energies in these systems (Figure SI-3). The contributions of N atoms to asphaltene-silica electrostatic interaction, as well as $\mathrm{S}$ atoms to the van der Waals interaction, are still prominent in the desorption process.

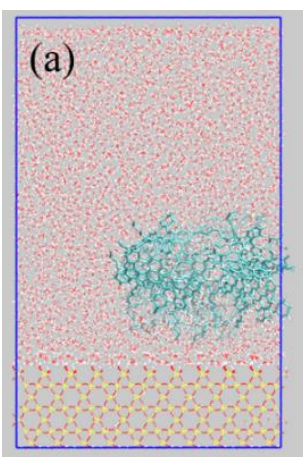

(c)

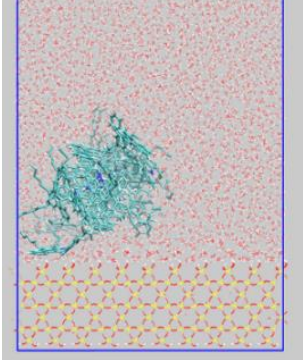

(e)

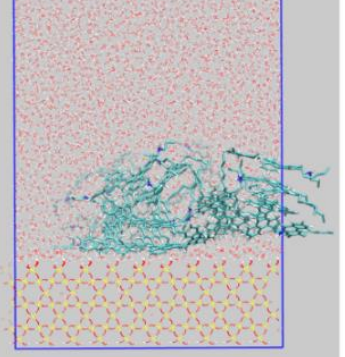

(b)

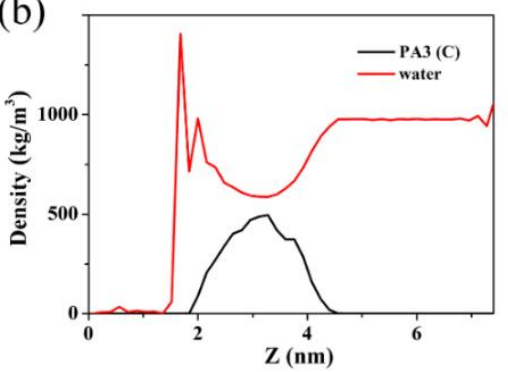

(d)

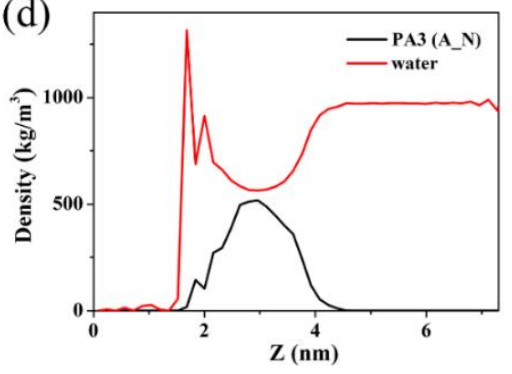

(f)

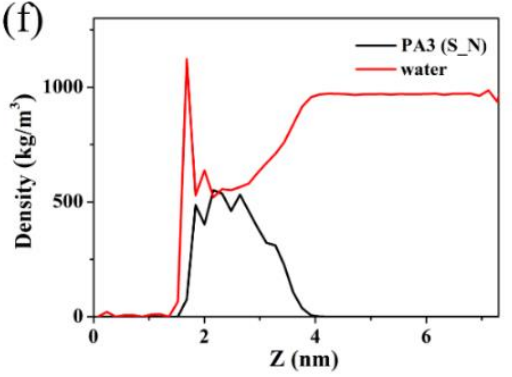

Figure 4. Equilibrium desorption conformation of asphaltene molecules (a) PA3 (C), (c) PA3 (A_N), (e) PA3 (S_N) on silica after 10-ns MD simulation; right side is the corresponding density distribution of asphaltene and water molecules along the Z-axis 
over the last $1 \mathrm{~ns}$.
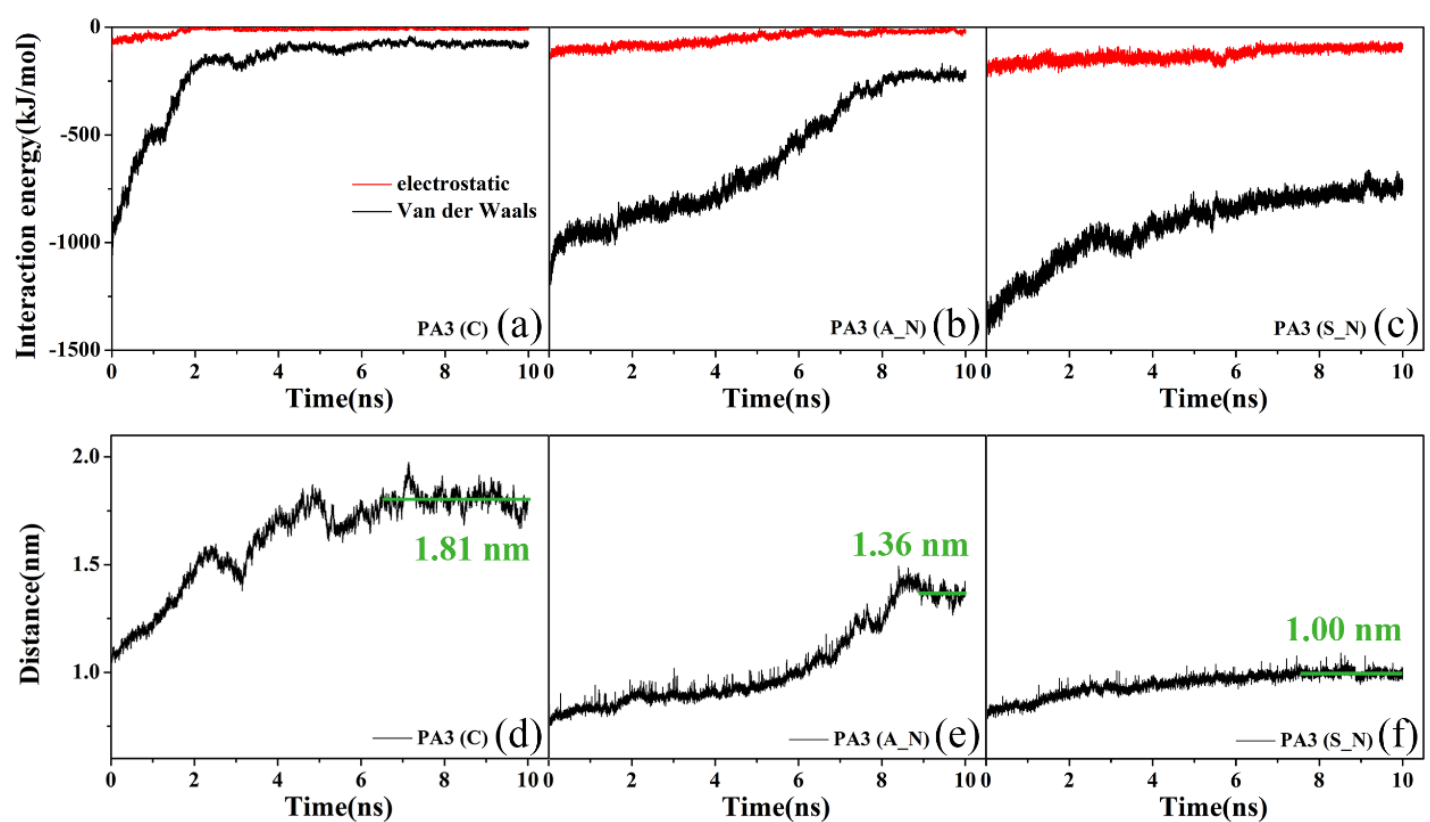

Figure 5. The interaction energies between asphaltenes (a) PA3 (C), (b) PA3 (A_N), (c)

PA3 (S_N) and silica as a function of simulation time; Average distance between COM as a function of simulation time.

\section{Effect of terminal polar groups}

Differing from the inside heteroatoms, the terminal polar groups including amino $\left(\mathrm{NH}_{2}\right)$, carboxyl $(\mathrm{COOH})$ and thiol $(\mathrm{SH})$ lead to extraordinary desorption properties of asphaltenes. These terminal polar groups have higher polarities and easier access to water molecules compared with the inside heteroatoms. They are able to interact closely surface. 
Figure 6 shows the initial and equilibrium conformations of the three kinds of asphaltenes in the desorption process. The asphaltene molecules are still adsorbed on the silica surface after 10-ns simulation due to the strong interaction between their polar groups and silica. Especially, there are remaining hydrogen bonds formed between the amino and carboxyl groups with silica hydroxyls. On the other hand, the asphaltene aggregates are reconstructed by the surrounding water molecules as a result of strong interaction with water. Driven by the water replacement on the silica surface, some asphaltene molecules are detached from the silica surface, while some parallel asphaltene molecules are forced to be more perpendicular and aggregate with adjacent asphaltenes. Consequently, the contact area of asphaltenes with silica is contracting and the asphaltene aggregates are more likely to form a droplet.

The number of hydrogen bonds formed between asphaltenes and silica, asphaltenes and water during the desorption process are also analyzed (Figure 7). The hydrogen bonds between asphaltenes and silica surface gradually decline with time, which is consistent with the decreasing interaction energies and morphologic change of the asphaltene aggregates. On the other hand, it is worth noticing that an average of 33 and 19 hydrogen bonds are formed between twenty PA3 $\left(\mathrm{NH}_{2}\right)$ and PA3 $(\mathrm{COOH})$ molecules with surrounding water respectively. The two types of hydrogen bonds also demonstrate the coexistence of strong asphaltene-silica and asphaltene-water interactions in the system containing terminal polar groups.

Not only enhancing the asphaltene-silica interaction, the terminal polar groups would also accelerate the detachment of asphaltenes by a different mechanism. When the 
411

412

413

414

415

416

417

418

419

420

421

422

terminal polar groups are present at the asphaltene/water interface, the interfacial tension will decrease quickly and the asphaltenes are more likely to detach.

However, strengthening the asphaltene-silica interaction is the dominant role of terminal polar groups, outweighing their ability to enhance the asphaltene-water binding. This is confirmed by the much higher interaction energies between asphaltenes containing terminal polar groups and silica in comparison with the original asphaltenes (Table 3). The strong electrostatic and van der Waals interactions, especially contributed by carboxyl and thiol respectively, are the major barrier to the detachment of asphaltenes from silica.

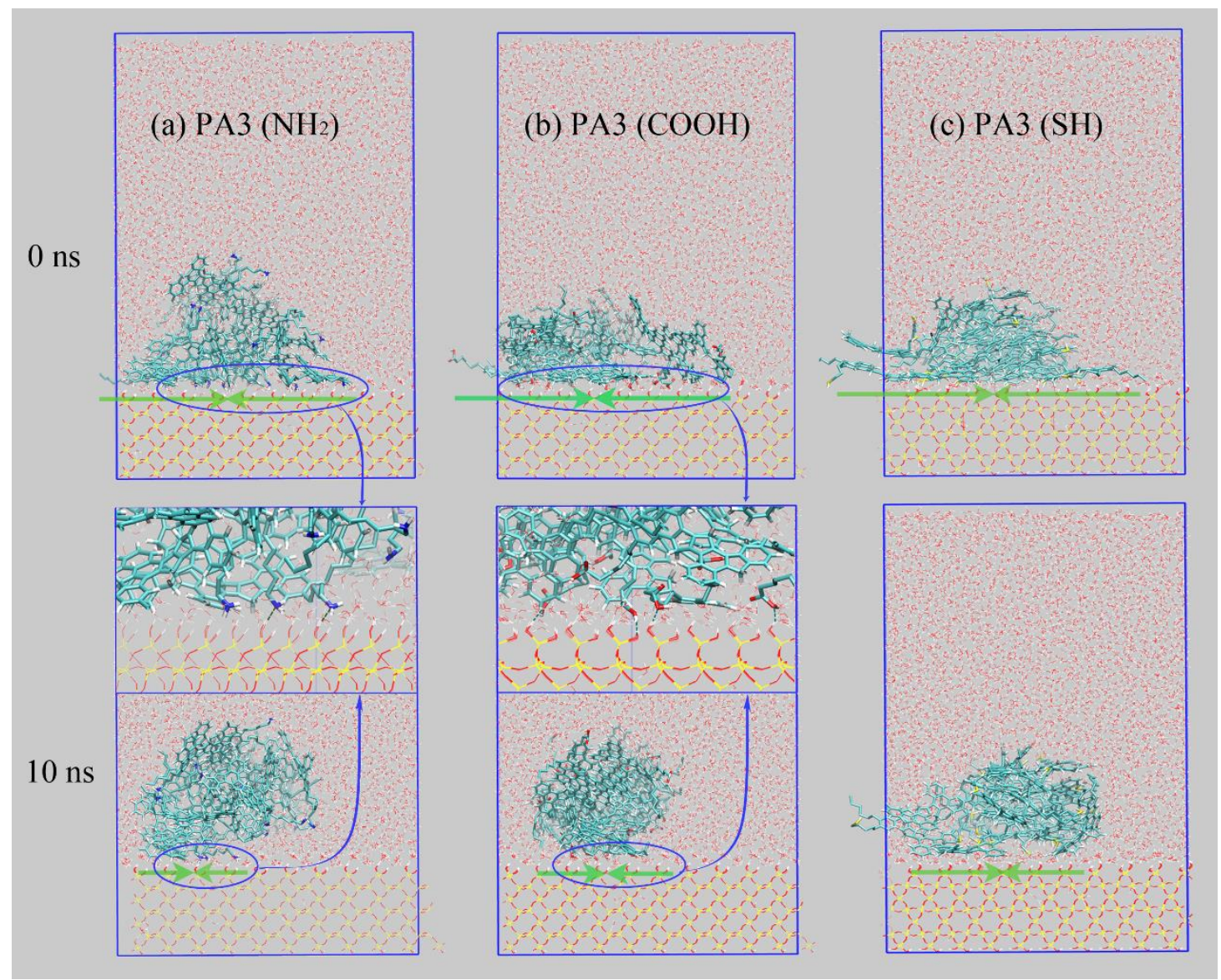

Figure 6. The initial ( $0 \mathrm{~ns})$ and equilibrium (10 ns) desorption conformation of asphaltene molecules (a) PA3 $\left(\mathrm{NH}_{2}\right)$, (b) PA3 (COOH), (c) PA3 (SH) on silica. 
Hydrogen bonds are shown by dashed lines in the enlarged views.

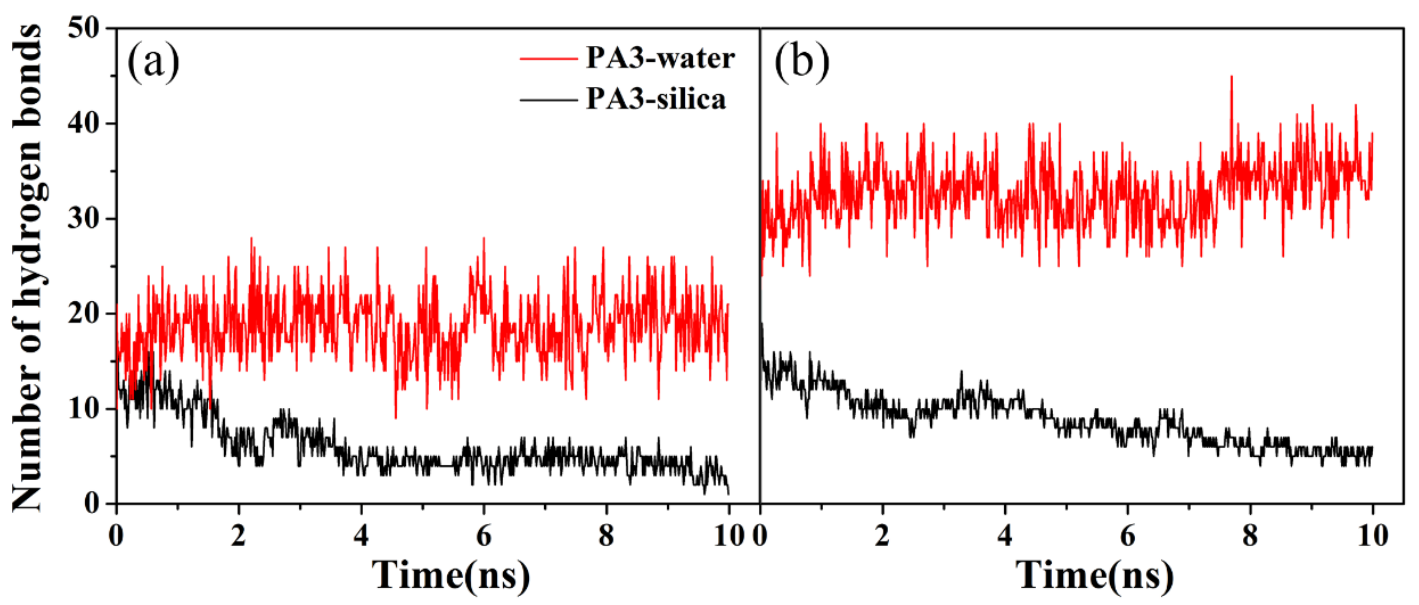

424

Figure 7. The number of hydrogen bonds between asphaltenes and silica, asphaltenes and water as a function of time: (a) PA3 $\left(\mathrm{NH}_{2}\right)$, (b) PA3 $(\mathrm{COOH})$.

Table 3. The electrostatic energies, van der Waals energies, and total interaction energies between asphaltenes and silica over the last $1 \mathrm{~ns}$

\begin{tabular}{cccc}
\hline $\begin{array}{c}\text { Interaction energy } \\
(\mathrm{kJ} / \mathrm{mol})\end{array}$ & $\mathrm{E}_{\text {ele }}$ & $\mathrm{E}_{\text {vdw }}$ & $\mathrm{E}_{\text {total }}$ \\
\hline PA3 $\left(\mathrm{NH}_{2}\right)$ & $-99.59 \pm 24.23$ & $-321.79 \pm 20.10$ & $-421.39 \pm 32.54$ \\
PA3 $(\mathrm{COOH})$ & $-184.32 \pm 21.29$ & $-470.58 \pm 31.18$ & $-654.90 \pm 36.27$ \\
PA3 $(\mathrm{SH})$ & $-62.53 \pm 9.04$ & $-502.89 \pm 17.08$ & $-565.43 \pm 20.55$ \\
\hline
\end{tabular}

\section{Conclusions}

The adsorption and desorption of asphaltenes containing heteroatoms $(\mathrm{N}, \mathrm{O}, \mathrm{S}$ at different positions) on the silica surface have been systematically investigated through molecular dynamics (MD) simulation. Different asphaltenes perform differently in the adsorption and desorption processes, depending on the type and position of heteroatoms. It is found that the terminal polar groups, especially carboxyl $(\mathrm{COOH})$, significantly enhance the asphaltene-silica electrostatic interactions; while the $\mathrm{S}$ atoms mainly 
437 contribute to the van der Waals interaction energies. Consequently, this enhanced polar 438 interactions between asphaltenes containing heteroatoms and silica hinder their 439 desorption from the surface. Both the equilibrium and dynamic properties including 440 desorption conformation, interaction energies, hydrogen bonds and COM distances 441 have confirmed the impeded partial desorption of asphaltenes with heteroatoms. 442 Additionally, when the terminal polar groups are present, the asphaltenes are partly 443 adsorbed on silica with remaining hydrogen bonds, while the asphaltene aggregates are 444 reconstructed by the surrounding water. Basically, strengthening the asphaltene-silica 445 interaction is the dominant role of terminal polar groups, outweighing their ability to 446 enhance the asphaltene-water binding. These findings would provide fundamental 447 information in understanding the influence of heteroatoms on the asphaltene adsorption 448 and desorption, which would also serve for developing novel technologies to recover 449 the unconventional petroleums or remediation of oil-contaminated soils. 


\section{Supporting Information}

453 The molecular structures and charge distribution in the model asphaltenes (Figure SI-

$4541)$.

455 The equilibrium adsorption conformations of PA3 (C) molecules at different loadings

$456(5,10,20,30)$ (Figure SI-2).

457 The interaction energies between O-containing, S-containing asphaltenes and silica as 458 a function of simulation time (Figure SI-3).

459 The cell parameters of the silica surface, binary adsorption system and ternary 460 desorption system (Tables SI-1 and SI-2 ).

461 AUTHOR INFORMATION

462 Corresponding authors:

$463 *$ E-mail: linhe@tju.edu.cn (L. He)

464 Notes:

465 The authors declare no competing financial interest.

466 ACKNOWLEDGEMENTS

467 This work was financially supported by the National Natural Science Foundation of 468 China (No. 21506155, No. 41471258). 


\section{REFERENCES}

470 [1] Lesueur D. The colloidal structure of bitumen: Consequences on the rheology and on the mechanisms

471 of bitumen modification. Adv Colloid Interface Sci 2009;145:42-82.

472 [2] Sheremata JM, Gray MR, Dettman HD, McCaffrey WC. Quantitative molecular representation and

473 sequential optimization of athabasca asphaltenes. Energy Fuels 2004;18:1377-84.

474 [3] Groenzin H, Mullins OC, Eser S, Mathews J, Yang M-G, Jones D. Molecular size of asphaltene 475 solubility fractions. Energy Fuels 2003;17:498-503.

476 [4] Dudášová D, Simon S, Hemmingsen PV, Sjöblom J. Study of asphaltenes adsorption onto different 477 minerals and clays. Colloids Surf, A 2008;317:1-9.

478 [5] Eyssautier J, Frot D, Barré L. Structure and dynamic properties of colloidal asphaltene aggregates.

479 Langmuir 2012;28:11997-2004.

480 [6] Branthaver JF, Petersen JC, Robertson RE, Duvall JJ, Kim SS, Harnsberger PM, Mill T, Ensley EK,

481 Barbour FA, Scharbron JF. Binder characterization and evaluation. Vol. 2: Chemistry, SHRP Report A-

368. Washington D. C.: National Research Council; 1994.

483 [7] He L, Lin F, Li XG, Sui H, Xu ZH. Interfacial sciences in unconventional petroleum production:

484 From fundamentals to applications. Chem Soc Rev 2015;44:5446-94.

485 [8] Scanlon BR, Reedy RC, Nicot J-P. Comparison of water use for hydraulic fracturing for unconventional oil and gas versus conventional oil. Environ Sci Technol 2014;48:12386-93.

487 [9] Adams JJ. Asphaltene adsorption, a literature review. Energy Fuels 2014;28:2831-56.

[10] López-Linares F, Carbognani L, González MF, Sosa-Stull C, Figueras M, Pereira-Almao P. asphaltene on macroporous solid surfaces. Energy Fuels 2006;20:2748-50. 
491 [11] Balabin RM, Syunyaev RZ, Schmid T, Stadler J, Lomakina EI, Zenobi R. Asphaltene adsorption 492 onto an iron surface: Combined near-infrared (NIR), raman, and AFM study of the kinetics, 493 thermodynamics, and layer structure. Energy Fuels 2011;25:189-96.

494 [12] Xiong Y, Cao TT, Chen Q, Li Z, Yang Y, Xu SM, Yuan SL, Sjöblom J, Xu ZH. Adsorption of a 495 polyaromatic compound on silica surfaces from organic solvents studied by molecular dynamics simulation and AFM imaging. J Phys Chem C 2017;121:5020-8.

497 [13] Hosseinpour N, Khodadadi AA, Bahramian A, Mortazavi Y. Asphaltene adsorption onto acidic/basic 498 metal oxide nanoparticles toward in situ upgrading of reservoir oils by nanotechnology. Langmuir 2013;29:14135-46.

[14] Liu JJ, Xu ZH, Masliyah J. Interaction forces in bitumen extraction from oil sands. J Colloid

501

502

503

504

505 506

507
Interface Sci 2005;287:507-20.

[15] Goncalves S, Castillo J, Fernandez A, Hung J. Absorbance and fluorescence spectroscopy on the aggregation behavior of asphaltene-toluene solutions. Fuel 2004;83:1823-8.

[16] Sodero ACR, Santos Silva H, Guevara Level P, Bouyssiere B, Korb J-P, Carrier H, Alfarra A, Begue D, Baraille I. Investigation of the effect of sulfur heteroatom on asphaltene aggregation. Energy Fuels 2016;30:4758-66.

[17] Silva HS, Sodero AC, Bouyssiere B, Carrier H, Korb J-P, Alfarra A, Vallverdu G, Bégué D, Baraille I. Molecular dynamics study of nanoaggregation in asphaltene mixtures: Effects of the N, O, and $\mathrm{S}$ heteroatoms. Energy Fuels 2016;30:5656-64.

[18] Buckley JS, Liu Y. Some mechanisms of crude oil/brine/solid interactions. J Pet Sci Eng 1998;20:155-60.

[19] Mendoza de la Cruz JL, Castellanos-Ramírez IV, Ortiz-Tapia A, Buenrostro-González E, Durán- 
513

514

515

516

517

518

519

520

521

522

523

524

525

526

527

528

529

530

531

532

533

534

Valencia CdlA, López-Ramírez S. Study of monolayer to multilayer adsorption of asphaltenes on reservoir rock minerals. Colloids Surf, A 2009;340:149-54.

[20] Turgman-Cohen S, Smith MB, Fischer DA, Kilpatrick PK, Genzer J. Asphaltene adsorption onto self-assembled monolayers of mixed aromatic and aliphatic trichlorosilanes. Langmuir 2009;25:6260-

69.

[21] Jouault N, Corvis Y, Cousin F, Jestin J, Barré L. Asphaltene adsorption mechanisms on the local scale probed by neutron reflectivity: Transition from monolayer to multilayer growth above the flocculation threshold. Langmuir 2009;25:3991-8.

[22] González MF, Stull CS, López-Linares F, Pereira-Almao P. Comparing asphaltene adsorption with model heavy molecules over macroporous solid surfaces. Energy Fuels 2007;21:234-41.

[23] Aggarwal V, Chien YY, Teppen B. Molecular simulations to estimate thermodynamics for adsorption of polar organic solutes to montmorillonite. Eur J Soil Sci 2007;58:945-57.

[24] Skartlien R, Simon S, Sjöblom J. DPD molecular simulations of asphaltene adsorption on hydrophilic substrates: Effects of polar groups and solubility. J Dispersion Sci Technol 2016;37:866-83.

[25] Wu GZ, He L, Chen DY. Sorption and distribution of asphaltene, resin, aromatic and saturate fractions of heavy crude oil on quartz surface: Molecular dynamic simulation. Chemosphere 2013;92:1465-71.

[26] Xiong Y, Li Z, Cao TT, Xu SM, Yuan SL, Sjoblom J, Xu ZH. Synergistic adsorption of polyaromatic compounds on silica surfaces studied by molecular dynamics simulation. J Phys Chem C 2018;122:42909.

[27] Li XG, Bai Y, Sui H, He L. Understanding the liberation of asphaltenes on the muscovite surface.

Energy Fuels 2017;31:1174-81. 
[28] Li XG, Bai Y, Sui H, He L. Understanding desorption of oil fractions from mineral surfaces. Fuel 2018;232:257-66.

[29] Shi C, Zhang L, Xie L, Lu X, Liu QX, He JJ, Mantilla CA, Zeng HB. Surface interaction of waterin-oil emulsion droplets with interfacially active asphaltenes. Langmuir 2017;33:1265-74.

[30] Poteau S, Argillier J-F, Langevin D, Pincet F, Perez E. Influence of pH on stability and dynamic properties of asphaltenes and other amphiphilic molecules at the oil-water interface. Energy Fuels 2005;19:1337-41.

[31] Berendsen HJ, van der Spoel D, van Drunen R. Gromacs: A message-passing parallel molecular dynamics implementation. Comput Phys Commun 1995;91:43-56.

[32] Van Der Spoel D, Lindahl E, Hess B, Groenhof G, Mark AE, Berendsen HJ. Gromacs: Fast, flexible, and free. J Comput Chem 2005;26:1701-18.

[33] Oostenbrink C, Villa A, Mark AE, Van Gunsteren WF. A biomolecular force field based on the free enthalpy of hydration and solvation: The GROMOS force-field parameter sets 53A5 and 53A6. J Comput Chem 2004;25:1656-76.

[34] Kuznicki T, Masliyah JH, Bhattacharjee S. Aggregation and partitioning of model asphaltenes at toluene-water interfaces: Molecular dynamics simulations. Energy Fuels 2009;23:5027-35.

[35] Sjoblom J, Simon S, Xu ZH. Model molecules mimicking asphaltenes. Adv Colloid Interface Sci $2015 ; 218: 1-16$

[36] Schuler B, Meyer G, Pena D, Mullins OC, Gross L. Unraveling the molecular structures of asphaltenes by atomic force microscopy. J Am Chem Soc 2015;137:9870-6.

[37] Kuznicki T, Masliyah JH, Bhattacharjee S. Aggregation and partitioning of model asphaltenes at toluene-water interfaces: Molecular dynamics simulations. Energy Fuels 2009;23:5027-35. 
557

558

559

560

561

562

563

564

565

566

567

568

569

570

571

572

573

574

575

576

577

578

[38] SchuÈttelkopf AW, Van Aalten DM. Prodrg: A tool for high-throughput crystallography of proteinligand complexes. Acta Crystallogr, D 2004;60:1355-63.

[39] Jian CY, Tang T, Bhattacharjee S. Probing the effect of side-chain length on the aggregation of a model asphaltene using molecular dynamics simulations. Energy Fuels 2013;27:2057-67.

[40] Zhu XZ, Chen DY, Wu GZ. Molecular dynamic simulation of asphaltene co-aggregation with humic acid during oil spill. Chemosphere 2015;138:412-21.

[41] Bussi G, Donadio D, Parrinello M. Canonical sampling through velocity rescaling. J Chem Phys 2007;126:014101.

[42] Darden T, York D, Pedersen L. Particle mesh ewald: An N. $\log (\mathrm{N})$ method for ewald sums in large systems. J Chem Phys 1993;98:10089-92.

[43] Reed LH, Allen LC. Bond polarity index: Application to group electronegativity. J Phys Chem 1992;96:157-64.

[44] Ta TD, Tieu AK, Zhu HT, Kosasih B. Adsorption of normal-alkanes on Fe(110), Feo(110), and $\mathrm{Fe}_{2} \mathrm{O}_{3}(0001)$ : Influence of iron oxide surfaces. J Phys Chem C 2015;119:12999-3010.

[45] Li CL, Choi P. Molecular dynamics study of the adsorption behavior of normal alkanes on a relaxed $\alpha-\mathrm{Al}_{2} \mathrm{O}_{3}$ (0001) surface. J Phys Chem C 2007;111:1747-53.

[46] Ni X, Choi P. Wetting behavior of nanoscale thin films of selected organic compounds and water on model basal surfaces of kaolinite. J Phys Chem C 2012;116:26275-83.

[47] Liu Q, Yuan SL, Yan H, Zhao X. Mechanism of oil detachment from a silica surface in aqueous surfactant solutions: Molecular dynamics simulations. J Phys Chem B 2012;116:2867-75.

[48] Zhang PL, Xu Z, Liu Q, Yuan SL. Mechanism of oil detachment from hybrid hydrophobic and hydrophilic surface in aqueous solution. J Chem Phys 2014;140:164702. 
579 [49] Chen JX, Si H, Chen WY. Molecular dynamics study of oil detachment from an amorphous silica 580 surface in water medium. Appl Surf Sci 2015;353:670-8.

581 [50] Li XF, Xue QZ, Zhu L, Jin YK, Wu TT, Guo QK, Zheng HX, Lu SF. How to select an optimal 582 surfactant molecule to speed up the oil-detachment from solid surface: A computational simulation. 583 Chem Eng Sci 2016;147:47-53.

584 [51] Vigil G, Xu ZH, Steinberg S, Israelachvili J. Interactions of silica surfaces. J Colloid Interface Sci $585 \quad 1994 ; 165: 367-85$.

586 [52] Abraham T, Christendat D, Karan K, Xu ZH, Masliyah J. Asphaltene-silica interactions in aqueous 587 solutions: Direct force measurements combined with electrokinetic studies. Ind Eng Chem Res $588 \quad 2002 ; 41: 2170-7$. 